\title{
Pilot study of exposure of the male population to organophosphate and pyrethroid pesticides in a region of high agricultural activity (Córdoba, Argentina)
}

\author{
Iohanna Filippi ${ }^{1}$ - Natalia Bravo ${ }^{2}$ - Joan O. Grimalt ${ }^{2}$ (D) Mariana Butinof $^{3} \cdot$ Daniel Lerda $^{4} \cdot$ Ricardo A. Fernández $^{4}$. \\ Sonia E. Muñoz ${ }^{5}$ - María V. Amé ${ }^{1}$
}

Received: 9 March 2021 / Accepted: 10 May 2021

(C) The Author(s), under exclusive licence to Springer-Verlag GmbH Germany, part of Springer Nature 2021

\begin{abstract}
Urinary metabolites of organophosphate (OP) and pyrethroid (PYR) pesticides and biomarkers of effects were studied in a population $(\mathrm{n}=40)$ residing in an important agricultural area of the province of Córdoba (Argentina). Detection frequencies (DF) higher than $85 \%$ were observed for the metabolites of pirimiphos (2-diethylamino-6-methylpyrimidin-4-ol -DEAMPY-, median $7.5 \mu \mathrm{g} / \mathrm{g}$ creatinine, DF: 100\%), parathion (p-nitrophenol, $0.99 \mu \mathrm{g} / \mathrm{g}$ creatinine, 100\%), and chlorpyrifos (3,5,6-trichloro2-pyridinol, $0.25 \mu \mathrm{g} / \mathrm{g}$ creatinine, $85 \%$ ). The DEAMPY concentrations doubled the levels found in other studies and were negatively associated with Er-AChE activity, suggesting the appearance of health effects already in environmental exposure levels below established acceptable daily intakes (ADIs). 3-Phenoxybenzoic acid, the metabolite of several PYR pesticides, was also found in all samples. This metabolite was also significantly negatively correlated with Er-AChE, indicating effects of pyrethroid pesticides on the acetylcholine system even at concentrations below the ADI.
\end{abstract}

Keywords Organophosphate pesticides $\cdot$ Pyrethroid pesticides $\cdot$ Human biomonitoring $\cdot$ Estimated daily intakes $\cdot$ Hazard quotients

Responsible Editor: Lotfi Aleya

Joan O. Grimalt

joan.grimalt@idaea.csic.es

1 Centro de Investigaciones en Bioquímica Clínica e Inmunología (CIBICI), Departamento de Bioquímica Clínica, Facultad de Ciencias Químicas, CONICET, Universidad Nacional de Córdoba, 5000 Córdoba, Argentina

2 Department of Environmental Chemistry, Institute of Environmental Assessment and Water Research (IDÆA-CSIC), 08034 Barcelona, Catalonia, Spain

3 Escuela de Nutrición, Facultad de Ciencias Médicas, Universidad Nacional de Córdoba, 5000 Córdoba, Argentina

4 Facultad de Ciencias de la Salud, Universidad Católica de Córdoba, 5000 Córdoba, Argentina

5 Instituto de Investigaciones en Ciencias de la Salud (INICSA), Facultad de Ciencias Médicas, CONICET, Universidad Nacional de Córdoba, 5000 Córdoba, Argentina

\section{Introduction}

Organophosphate (OP) and pyrethroid (PYR) pesticides are widely used in agriculture, commercial buildings, homes, and home gardens for insect control. Unfortunately, the neurotoxic effects of these pesticides are not selective enough to prevent harm to other non-target species, including humans (Barr 2008; Bjørling-Poulsen et al. 2008; Jokanović 2018). Neurological effects, e.g., Parkinson's disease, endocrine disruption, genotoxicity, and cancer, have been correlated with chronic exposure to low doses of OP pesticides (Bolognesi 2003; Hancock et al. 2008; Koureas et al. 2012; McKinlay et al. 2008; Manthripragada et al. 2010; Rohlman et al. 2011). On the other hand, endocrine disruption and alteration in male reproduction have been related to exposure to low-dose PYR pesticides (McKinlay et al. 2008; Perry et al. 2007). The general population can incorporate pesticides through domestic use and the consumption of contaminated food and beverages, with ingestion being the main route of exposure. Populations living in nearby agricultural areas can also be exposed through inhalation of polluted air (Yusa et al. 2015a). 
Organophosphate pesticides are metabolized to dialkyl phosphates (DAP) and organic moieties. The most common PYR pesticides, including permethrin, cypermethrin, and deltamethrin, are metabolized to 3-phenoxybenzoic acid (3PBA), while cyfluthrin is metabolized to 4-fluoro-3phenoxybenzoic acid (4-F-3-PBA). The determination of the organic metabolite moieties in the urine provides information on the internal doses of the specific parental compounds that allows assessing the exposure to individual pesticides (Barr et al. 2002; Barr 2008; Koureas et al. 2012; Bravo et al. 2019, 2020a, b).

Recently, interest in human biomonitoring for the estimation of internal exposure doses has grown due to the increasing information available on the human impact of environmental chemicals (Bravo et al. 2019, 2020a, b; Garí et al. 2018; Yusa et al. 2015b). The concentrations of OP and PYR pesticide metabolites found in human urine allow evaluating exposure to parent pesticides and calculating estimated daily intakes (EDI) that can be compared with acceptable daily intakes (ADI; Phung et al. 2012; Katsikantami et al. 2019) and hazard quotients (HQ) to assess exposure to pesticides.

The inhibition of acetylcholinesterase (AChE) is one of the most immediate toxic effects of OP pesticides (Fukuto 1990). Therefore, determination of AChE activity in plasma ( $\mathrm{Pl}-$ $\mathrm{AChE}$ ) and erythrocytes (Er-AChE) is commonly used to assess health effects after exposure to them. Since some pesticides are also mutagenic, various genotoxicity biomarkers, such as micronuclei (MN), are used to assess genotoxic responses to pesticide exposure (Bolognesi 2003). However, little is known about the interaction between exposure to specific individual pesticides and these effects which, depending on differences in chemical properties and toxic modes of action, can result in diverse responses (Hernández et al. 2013).

Argentina is a developing country and one of the main crop producers in South America. The amount of commercialized pesticides doubled in the last 18 years, from 140 million $\mathrm{kg} / \mathrm{L}$ in 1998 (Moltoni 2012) to 340 million $\mathrm{kg} / \mathrm{L}$ in 2016 (CASAFE 2016). Insecticides rank second in sales with a total of 17 million $\mathrm{kg} / \mathrm{L}$ in 2016 (CASAFE 2016). The frontiers of cultivation have expanded in the province of Córdoba, where the number of hectares dedicated to soybean cultivation has almost doubled in this period and the number of hectares dedicated to corn and wheat cultivation has almost tripled between 1999/2000 and 2017/2018 (MAGyP 2018).

Previous cross-sectional studies in subjects occupationally exposed to pesticides in the province of Córdoba (Butinof et al. 2014, 2019; Lantieri et al. 2011) showed a high prevalence of acute and subacute health disorders that could be related with the application of these compounds. However, a direct assessment of the general population exposure to OP and PYR pesticides in this high agricultural activity area had not been performed. The present paper is dedicated to provide a first pilot study of the subjects of the province of Córdoba that inhabit areas of intensive use of OP and PYR to evaluate their exposure to these pesticides.

\section{Materials and methods}

\section{Study area, population, and questionnaires}

The Center-East of the province of Córdoba corresponds to the Homogeneous Ecological Area VI where the main economic activity is agriculture (INTA 2009). This area is the main producer of soybeans and the third producer of corn and wheat in the province (MAGyP 2018). The main technology used to apply pesticides was by self-propelled machinery having a pressurized cabin equipped with an activated charcoal filter to allocate the applicators. No significant horticultural activities are registered in the studied area. The sampling date (September 2019) was chosen in the pesticide application period. All subjects were selected from a previous cohort from the same area (Butinof et al. 2019). In this previous study, terrestrial pesticide applicators were men in all cases. As many studies mention gender as a determinant factor affecting pesticides concentrations and health parameters, men were also chosen as the reference population of non-applicator subjects living in this area of intensive use of pesticides (Saoudi et al. 2014; Schettgen et al. 2015). Consequently, we continued working with these male populations. No incentives were offered to participants.

All participants $(\mathrm{N}=40)$ were subjects over 18 years of age, residing in the province of Córdoba for at least the last 5 years, and capable of giving their consent in writing. They were contacted by phone, and those who agreed to participate went to the local health center (95\% acceptance) and signed a written informed consent before the delivery of the sample.

All participants were requested to answer a medical history survey, including diagnoses of chronic diseases related to pesticides exposure, and sociodemographic data. This information was collected by trained interviewers following a validated structural questionnaire (Becaria Coquet et al. 2020). In order to avoid any interference with measured biochemical parameters, individuals presenting diabetes, neurological disorders, liver dysfunction, and any other chronic condition or subjects under pharmacological therapy, chemotherapy/ radiotherapy treatment, recent surgeries, and viral diseases were excluded. Participants reporting alcoholism and drug addiction were also excluded.

Age, height, weight, body mass index (BMI), educational level, distance from home to the nearest crop, and units of vegetables and fruits consumed were registered as possible determinants of pesticide exposure. Self-reported anthropometric characteristics were used to estimate BMI $\left(\mathrm{kg} / \mathrm{m}^{2}\right)$. Normal BMI was considered between 18.5 and $24.9 \mathrm{~kg} / \mathrm{m}^{2}$, overweight between 25.0 and $29.9 \mathrm{~kg} / \mathrm{m}^{2}$, and obesity $>30 \mathrm{~kg} /$ 
$\mathrm{m}^{2}$ (Becaria Coquet et al. 2020). Educational level was categorized as elementary, middle, high school, or university, while distance from home to the nearest crop was categorized as $<100 \mathrm{~m},>100-500 \mathrm{~m}$, or $>500 \mathrm{~m}$.

The proposal was approved by the Ethics Review Committee of Hospital Nacional de Clínicas and is enrolled in the Ethics Committee of Health Investigations of the Córdoba Province (RePIS N ${ }^{\circ} 1582$ and 044/10).

\section{Collection of biological samples}

After an overnight fasting period, samples of venous blood were collected in different tubes, one EDTA-treated and the other heparin-treated, and preserved cooled at $4-8^{\circ} \mathrm{C}$ until they reached the laboratory. EDTA blood samples were analyzed upon arrival at the laboratory to measure $\mathrm{AChE}$ activity. Heparin samples were used to evaluate MN. Urine samples were collected in sterile containers and kept cold at $4-8^{\circ} \mathrm{C}$ until reaching the laboratory and then samples were stored at $-20^{\circ} \mathrm{C}$ until pesticide analysis.

\section{Exposure biomarkers}

Six specific OP pesticide metabolites (TCPY, PNP, MDA, CMHC, IMPY, DEAMPY) and two PYR pesticide metabolites (3-PBA and 4-F-3-PBA) were measured.

\section{Laboratory analysis}

Sample preparation and analysis were performed as described in Garí et al. (2018). Briefly, urine samples were centrifuged and filtered. Then, $1 \mathrm{~mL}$ of the filtered samples was collected, and $10 \mu \mathrm{L}$ of a mixture of the available isotopically labeled internal standards was added. $\beta$-glucuronidase was used to hydrolyze possible glucuronide and sulfate-conjugated metabolites. Samples were incubated overnight at $37^{\circ} \mathrm{C}$. Then, they were extracted and cleaned up using solid phase extraction (SPE) cartridges (Oasis HLB $3 \mathrm{~cm}^{3}, 60 \mathrm{mg}$ ). These cartridges were preconditioned with $1 \mathrm{~mL}$ of methanol:acetone $(25: 75$ $\mathrm{v} / \mathrm{v}$ ) followed by $1 \mathrm{~mL}$ of HPLC $\mathrm{H}_{2} \mathrm{O}$ (1\% acetic acid), and then the samples were passed through the cartridges. After this step, they were washed with $500 \mu \mathrm{L}$ of HPLC $\mathrm{H}_{2} \mathrm{O}(1 \%$ acetic acid) and dried for $20 \mathrm{~min}$ under vacuum. Finally, elution was made using $1.5 \mathrm{~mL}$ of a solution containing methanol:acetone $(25: 75 \mathrm{v} / \mathrm{v})$. The collected extracts were reduced to dryness under a gentle stream of pure nitrogen. The concentrates were reconstituted in $120 \mu \mathrm{L}$ of methanol:water $(25: 75 \mathrm{v} / \mathrm{v})$.

\section{Instrumental analysis}

Identification and quantification of the pesticide metabolites were carried out using an ultra-performance liquid chromatography (UPLC Acquity H-class, Waters, Milford, MA, USA) coupled to a triple quadrupole mass spectrometer (XEVO-TQS, Waters, Milford, MA, USA) equipped with an electrospray ionization (ESI) interface. Chromatographic separation was achieved on a Betasil $\mathrm{C}_{18}$ column $(100 \mathrm{~mm} \times 2.1 \mathrm{~mm}, 3 \mu \mathrm{m}$ particle size, Thermo Scientific, West Palm Beach, FL, USA). Injection volume was $10 \mu \mathrm{L}$, at a flow rate of $0.3 \mathrm{~mL} / \mathrm{min}^{\mathrm{a}}$. Column temperature was kept at $30{ }^{\circ} \mathrm{C}$ during the analysis. Mobile phase of acetonitrile and a mixture of $\mathrm{HPLC}_{2} \mathrm{O}$ with $1 \%$ acetic acid and 5\% methanol were used in different proportions during the analysis. Data was processed using the Masslynx software version 4.1 (Waters Inc., 2008).

\section{Quality control}

Quality control materials, blanks, and calibration curves were made using synthetic urine (Surine, Preserve Free, SigmaAldrich). The accuracy of the method was assessed at two concentration levels: $1 \mu \mathrm{g} / \mathrm{L}$ and $10 \mu \mathrm{g} / \mathrm{L}$. The calibration curves were prepared by adding $25 \mu \mathrm{L}$ of standard solutions into $1 \mathrm{~mL}$ of synthetic urine sample, yielding final concentrations between 0.06 and $13.3 \mu \mathrm{g} / \mathrm{L}$. Limits of detection (LOD) were in the ranges of $0.014-0.069 \mu \mathrm{g} / \mathrm{L}$ and $0.018-0.019$ $\mu \mathrm{g} / \mathrm{L}$ for $\mathrm{OP}$ and PYR metabolites, respectively. Quantification was performed by using isotopically labeled internal standards. The selected reaction monitoring (SRM) transitions for each compound were the same as those reported by Garí et al. 2018; Supplementary Material SM-Table SM1). The most abundant transition was used for quantification (QSRM) and the second for confirmation (C-SRM). In addition to the retention times, the relative abundances of the SRM transitions were used to identify the metabolites in the samples and to discriminate possible coelutions. Ion ratios (IRs = Q$\mathrm{SRM} / \mathrm{C}$-SRM) of the samples should not differ by $\pm 20 \%$ from the standard solutions for positive coelution-free identification.

\section{Effect biomarkers}

Er-AChE and Pl-AChE were determined by spectrophotometric assay (Ellman et al. 1961) using a commercial kit (Roche Diagnostics GmbH, Mannheim, Germany) according to the manufacturer's instructions. Determination of Pl-AChE was carried out using plasma obtained from centrifugation of whole blood (10 min-1500 g). Er-AChE determination was achieved using a hemolyzed of whole blood in distilled water.

The micronuclei assays were performed according to Bolognesi et al. (1993). Whole blood $(0.4 \mathrm{~mL})$ was added to $4.5 \mathrm{~mL}$ of RPMI 1640 complete medium and $10 \%$ fetal calf serum with $1 \%$ phytohaemoagglutinin. Cells were cultivated at $37^{\circ} \mathrm{C}$ for $72 \mathrm{~h}$ with the addition of cytochalasin $\mathrm{B}$ after $44 \mathrm{~h}$ (final concentration $6 \mu \mathrm{g} / \mathrm{mL}$ ). After incubation, samples were centrifuged ( $500 \mathrm{~g}-10 \mathrm{~min})$, resuspended in buffer $(0.9 \mathrm{mM}$ $\mathrm{NH}_{4} \mathrm{HCO}_{3}$ and $132 \mathrm{mM} \mathrm{NH}_{4} \mathrm{Cl}$ ) for $20 \mathrm{~min}$, and centrifuged 
again $(1500 \mathrm{~g}-15 \mathrm{~min})$. This procedure was repeated twice. After that, cells were fixed in cold fixative (methanol:acetic acid 3:1) for $20 \mathrm{~min}$. Cell suspensions were carefully dropped onto wet slides. Samples were air dried and stained with $3 \%$ Giemsa in distilled water and mounted. The frequency of binucleated cells with micronuclei was determined by scoring a total of 2000 binucleated lymphocytes with preserved cytoplasm.

Creatinine was spectrophotometrically measured by the Jaffe reaction using a commercial kit. This protein was used as reference in reporting the individual metabolite concentrations.

\section{Calculation of estimated daily intakes and hazard quotients}

OP and PYR pesticide daily intakes were estimated using the following toxicokinetic model (Eq. (1); Katsikantami et al. 2019):

$\operatorname{EDI}\left(\frac{\frac{\mu g}{\mathrm{Kg} \mathrm{bw}}}{\mathrm{d}}\right)=\frac{\mathrm{C}_{\mathrm{U}}\left(\frac{\mu \mathrm{mol}}{\mathrm{L}}\right) * \mathrm{~V}_{\mathrm{U}}(\mathrm{L}) * \mathrm{MW}_{\mathrm{P}}\left(\frac{\mathrm{g}}{\mathrm{mol}}\right)}{\mathrm{F}_{\mathrm{UE}} * \mathrm{BW}(\mathrm{Kg})}$

where EDI is the estimated daily intake, $\mathrm{C}_{\mathrm{U}}$ is the molar concentration of metabolite, $\mathrm{V}_{\mathrm{U}}$ is the total urinary volume excreted within $24 \mathrm{~h}, \mathrm{MW}_{\mathrm{P}}$ is the molecular weight of the parent compound, and $\mathrm{F}_{\mathrm{UE}}$ is the urinary excretion factor of the parent compound and BW the body weight.

HQs were calculated using the ratio between EDIs and acceptable daily intakes (ADIs) reported by the Food and Agriculture Organization (FAO) in their Joint Meetings on Pesticides Residues (JMPR 2020).

\section{Statistical analysis}

Baseline characteristics of the results were first described as geometric means, medians, standard deviations, and quantiles. These outcomes were calculated using the full analysis set. Correlations between biomarkers were calculated as Pearson coefficient. p-values under 0.05 were considered significant. When the value was under LOD, half of the limit of detection was used for the statistical evaluations. The analyses were performed with Stata@ version 2014.

\section{Results}

\section{Sociodemographic characteristics}

A total of 40 subjects participated in the study. The sociodemographic characteristics of the population are shown in Table 1 . The average age was 44 years old. More than $50 \%$
Table 1 Sociodemographic characteristics of the studied population from Córdoba province

\begin{tabular}{ll}
\hline Sociodemographic characteristics & Mean $(\%)$ \\
\hline Age & 44 \\
Height $(\mathrm{m})$ & 1.76 \\
Weight $(\mathrm{kg})$ & 87.9 \\
BMI $^{\mathrm{a}}$ & 28.4 \\
Normal & $10(25)$ \\
Overweight & $20(50)$ \\
Obesity & $10(25)$ \\
Smoking & $3(7.5)$ \\
Educational level & \\
Elementary & \\
Middle & $4(10)$ \\
High school & $5(12.5)$ \\
University & $21(52.5)$ \\
Distance between home and the nearest crop & \\
$<100 \mathrm{~m}$ & $10(25)$ \\
$>100-500 \mathrm{~m}$ & \\
$>500 \mathrm{~m}$ & $3(7.5)$ \\
\hline
\end{tabular}

${ }^{\mathrm{a}}$ BMI (body mass index, $\mathrm{kg} / \mathrm{m}^{2}$ )

${ }^{\mathrm{b}}$ Educational level was categorized as elementary (1), middle (2), high school (3), and university (4)

${ }^{\mathrm{c}}$ Distance from home to the nearest crop was categorized as $<100 \mathrm{~m}$ (1), $>100-500 \mathrm{~m}(2)$, and $>500 \mathrm{~m}$ (3).

were overweight or obese. Thirty-one of the participants had completed at least the secondary level. More than half of the volunteers lived within $500 \mathrm{~m}$ of the fields. The three smokers were excluded from the genotoxicological analysis. Weekly average consumption of vegetables and fruits was 20 and 11 units, respectively.

\section{Exposure biomarkers}

Detection frequencies (DF) were calculated using the concentrations above the LOD (in $\mu \mathrm{g} / \mathrm{L}$; Table 2). The DEAMPY, PNP, and 3-PBA pesticide metabolites were the most frequently found in the total population (100\%) followed by TCPY (85\%) and the specific PYR metabolite, 4-F-3-PBA (35\%). The OP metabolite IMPY was found in four samples and MDA was detected once, while CMHC was not detected in any of the samples.

\section{Effect biomarkers}

Mean \pm standard deviation of the AChE activity in plasma and erythrocytes, Er-AChE and Pl-AChE, were $14000 \pm$ $4100 \mathrm{U} / \mathrm{L}$ and $4400 \pm 1200 \mathrm{U} / \mathrm{L}$, respectively. The mean 
Table 2 Exposure biomarkers in $\mu \mathrm{g} / \mathrm{g}$ creatinine and $\mu \mathrm{g} / \mathrm{L}$ measured in the total population studied $(\mathrm{N}=40)$ from the Córdoba province. The results are expressed as detection frequencies (DF), geometric mean
(GM), confidence interval (CI), median, and range of 95th percentile (p95). When the result was $<$ LOD, half of the LOD was used

\begin{tabular}{|c|c|c|c|c|c|c|c|c|c|c|c|c|c|}
\hline \multirow[t]{2}{*}{ Metabolite } & \multirow[b]{2}{*}{$\mathrm{LOD}(\mu \mathrm{g} / \mathrm{L})$} & \multirow[b]{2}{*}{$\mathrm{n}$} & \multirow[b]{2}{*}{$\mathrm{DF}(\%)$} & \multicolumn{5}{|c|}{$\mu \mathrm{g} / \mathrm{g}$ creatinine } & \multicolumn{5}{|l|}{$\mu \mathrm{g} / \mathrm{L}$} \\
\hline & & & & GM & CI & Median & Range & p95 & GM & CI & Median & Range & p95 \\
\hline DEAMPY & 0.017 & 40 & 100 & 5.3 & $3.2-8.5$ & 7.5 & $0.28-48$ & 27 & 8.0 & $5.0-13$ & 11 & $0.37-50$ & 46 \\
\hline IMPY & 0.014 & 4 & 10 & $<\mathrm{LOD}$ & & $<\mathrm{LOD}$ & nd- 0.25 & 0.11 & $<\mathrm{LOD}$ & & $<\mathrm{LOD}$ & nd- 0.25 & 0.17 \\
\hline MDA & 0.069 & 1 & 2.5 & $<$ LOD & & $<\mathrm{LOD}$ & nd-5.3 & $<\mathrm{LOD}$ & $<\mathrm{LOD}$ & & $<\mathrm{LOD}$ & nd-5.0 & $<\mathrm{LOD}$ \\
\hline PNP & 0.017 & 40 & 100 & 0.92 & $0.66-1.3$ & 0.99 & $0.14-6.9$ & 6.2 & 1.4 & $1.0-1.9$ & 1.5 & $0.21-6.6$ & 6.2 \\
\hline TCPY & 0.020 & 34 & 85 & 0.20 & $0.10-0.39$ & 0.25 & nd-4.3 & 2.6 & 0.30 & $0.15-0.58$ & 0.48 & nd-4.0 & 3.0 \\
\hline CMHC & 0.026 & 0 & 0 & $<\mathrm{LOD}$ & & $<\mathrm{LOD}$ & - & $<\mathrm{LOD}$ & $<\mathrm{LOD}$ & & $<\mathrm{LOD}$ & & $<\mathrm{LOD}$ \\
\hline 3-PBA & 0.018 & 40 & 100 & 2.3 & $1.9-2.8$ & 2.2 & $0.98-7.5$ & 6.5 & 3.5 & $2.8-4.3$ & 2.7 & $1.2-16$ & 15 \\
\hline 4-F-3-PBA & 0.019 & 14 & 35 & $<$ LOD & & $<\mathrm{LOD}$ & nd- 0.20 & 0.14 & 0.026 & $0.016-0.042$ & $<$ LOD & nd- 0.25 & 0.18 \\
\hline
\end{tabular}

and standard deviation of the frequencies of binucleated cells with micronuclei were $9.2 \pm 2.6$.

\section{Correlations}

Pearson correlations between biomarkers and sociodemographic parameters were also calculated (data not shown). No associations were found between biomarkers and age, weight, BMI, marital status, and distance from home to the nearest crop. Only a negative association was found between the 4-F3-PBA metabolite and educational level (p-value 0.0017)

Pearson coefficients were calculated to evaluate the correlations between biomarkers of effect and exposure (Table 3). MNs were not associated with any OP or PYR metabolites. A significant negative association was observed between Er-AChE and the OP pesticide found in the highest concentration, DEAMPY $(\mathrm{p}<0.01)$. A significant correlation was also observed between lower Er$\mathrm{AChE}$ and higher concentrations of the general PYR pesticide metabolite, 3-PBA $(\mathrm{p}<0.05)$.

\section{Discussion}

\section{Exposure biomarkers}

The detection frequencies of the OP pesticide metabolites in the present study were comparable to findings in Spain, Thailand, the USA, and China (Arcury et al. 2009; Davis et al. 2013; Garí et al. 2018; Le Grand et al. 2011; Olsson et al. 2003; Panuwet et al. 2008; Perry et al. 2007; Raymer et al. 2014; Wang et al. 2016; SM-Tables SM2 and SM3). The use of coumaphos, diazinon, parathion, and malathion is prohibited in Argentina according to the resolutions SAGPyA 532/2011, MSN 456/2009, SAGPyA 606/93, and MSN 2158/2017, respectively.

However, the high frequency detection of PNP in the present study suggests that the population has recently been exposed to parathion and parathion-methyl. The PNP metabolite levels in the present study were similar to those found in Thailand, Spain, Australia, Puerto Rico, and the USA (Garí et al. 2018; Heffernan et al. 2016; Lewis et al. 2015; Olsson et al. 2003; Panuwet et al. 2008; SM- Tables SM2 and SM3). Perry et al. (2007) reported a higher mean PNP concentration
Table 3 Pearson correlation between effect and exposure biomarkers of total population exposed to pesticides from the Córdoba province

\begin{tabular}{|c|c|c|c|c|c|c|}
\hline \multirow[t]{2}{*}{ Metabolite } & \multicolumn{2}{|l|}{ Er-AChE } & \multicolumn{2}{|l|}{ Pl-AChE } & \multicolumn{2}{|l|}{$\mathrm{MN}$} \\
\hline & Pearson coef. & $\mathrm{p}$-value & Pearson coef. & p-value & Pearson coef. & p-value \\
\hline DEAMPY & -0.4712 & 0.0056 & 0.1509 & 0.4018 & -0.2528 & 0.1777 \\
\hline PNP & -0.1623 & 0.3669 & -0.0067 & 0.9705 & 0.0018 & 0.9926 \\
\hline TCPY & -0.0705 & 0.6966 & 0.2073 & 0.2471 & -0.2549 & 0.1741 \\
\hline 3-PBA & -0.3530 & 0.0439 & 0.0036 & 0.9841 & -0.2889 & 0.1215 \\
\hline 4-F-3-PBA & 0.1809 & 0.3109 & 0.1284 & 0.4763 & 0.2096 & 0.2663 \\
\hline
\end{tabular}


$(5.3 \mu \mathrm{g} / \mathrm{L})$ than in the present study for people who have family members who live and work on farms. Raymer et al. (2014) also found higher geometric mean concentrations of the PNP metabolite $(7.67 \mu \mathrm{g} / \mathrm{L})$ than in our study in agricultural workers who do not apply pesticides but live on the farm. PNP could also come from other sources besides the use of parathion, but as far as we know, there are no industries capable of producing PNP residues in the surroundings of the study area. The urinary PNP metabolite can also result from exposure to environmental PNP resulting from natural environmental degradation of parathion or methyl parathion. However, considering the high reactivity of parathion and its low persistence in environmental samples, PNP concentrations probably reflect recent contributions in the studied cohort (Bravo et al. 2019). After acute exposures, most of the metabolites are rapidly excreted in the urine (Abu-Qare and Abou-Donia 2000; Braeckman et al. 1983), but chronic exposures to parathion and parathion-methyl, as well as with any non-persistent organic toxicant, can result in steady-state metabolite excretion.

In comparison with similar studies carried out in general and occupationally exposed populations, the geometric mean and median concentration of the metabolite DEAMPY in the present study were at least two times higher than those measured in Spain and the USA (Garí et al. 2018; Olsson et al. 2003; Raymer et al. 2014, Table SM3). The TCPY concentrations for this Argentinean population were generally lower than those reported in Thailand, the USA, and Germany (Koch et al. 2001; Morgan 2015; Panuwet et al. 2008).

The concentrations of 3-PBA in these Argentinean subjects were similar to those from studies conducted in occupationally exposed populations from Spain and the USA (Garí et al. 2018; Raymer et al. 2014; Table SM2) but higher, at least 2 times, than in studies conducted in general population from France, China, and the USA (Le Grand et al. 2011; Morgan 2015; Perry et al. 2007; Trunnelle et al. 2014; Table SM3). Generally, the concentrations of the metabolite 4-F-3-PBA were low and similar to those found in Spain, Germany, and the Caribbean Countries (Dewailly et al. 2014; Garí et al. 2018; Heudorf and Angerer 2001).

\section{Effect biomarkers}

The mean and standard deviation of the frequencies of binucleated cells with micronuclei, $9.2 \pm 2.6$, were comparable with results obtained in other studies carried out on Argentinean populations (Butinof et al. 2019; Gentile et al. 2012).

The Er-AChE and Pl-AChE values were within standard intervals, $12,000-17,000 \mathrm{U} / \mathrm{L}$ and $1700-5800 \mathrm{U} / \mathrm{L}$, respectively, with some subjects showing activities of $\mathrm{AChE}$ out of the range. However, the significant negative correlation observed between Er-AChE and DEAMPY was showing an influence of the most abundant OP pesticide in the cholinesterase activity of the exposed cohort subjects. This result therefore evidences an observable toxic effect within standard intervals.

The correlation between lower Er-AChE and higher 3-PBA concentrations was unexpected because no cholinergic effects had been previously described for PYR pesticides. However, these compounds are sometimes sprayed in combination with OP pesticides. Therefore, the indirect influence of OP pesticides on the lowest observed Er-AChE could not be excluded a priori. However, no statistically significant correlation was observed between 3-PBA and metabolites of OP pesticides, making an influence of OP pesticides on the observed correlation between Er-AChE and 3-PBA unlikely. However, CYP450 activation mediated by exposure to the OP pesticides decreases the metabolization of PYR pesticides due to the inhibition of esterases and, consequently, increases the toxicity of the latter (Hernández et al. 2013).

\section{Estimated daily intakes and hazard quotients}

The EDI and HQ calculations are summarized in Table 4. For the DEAMPY metabolite, we could not find the $\mathrm{F}_{\mathrm{UE}}$ value, and consequently the EDI was not calculated. For 3-PBA, the individual and average molecular weights and ADIs of permethrin, cypermethrin, and deltamethrin, the three most commonly sprayed PYR pesticides in Argentina were used. No HQs exceeded unity, indicating that the calculated EDIs were within safe values according to FAO (JMPR 2020). These results were consistent with observations from other studies for chlorpyrifos (Phung et al. 2012), diazinon, malathion, and parathion (Katsikantami et al. 2019).

However, the observed correlation between Er-AChE and DEAMPY suggests that with median EDIs of 0.16 $\mu \mathrm{g} / \mathrm{kg} \mathrm{bw} / \mathrm{d}$ and $0.17 \mu \mathrm{g} / \mathrm{kg}$ bw/d for parathion and parathion-methyl (Table 4), there was still a submicron effect of these compounds in the AChE system despite the recommended ADIs of 3-4 $\mu \mathrm{g} / \mathrm{kg}$ bw/d. The same occurs with pyrethroid pesticides in which the observed IEDs, $0.46-0.60 \mu \mathrm{g} / \mathrm{kg}$ bw/d (Table 4), also correspond to an effect of these compounds on the AChE system despite the fact that they are lower than the indicated ADIs of 10 $50 \mu \mathrm{g} / \mathrm{kg} \mathrm{bw} / \mathrm{d}$.

\section{Conclusions}

The present study is the first report on biomonitoring of pesticide residues in urine samples from a population in Argentina. DEAMPY was the metabolite found in the highest concentration, which indicates the use of 
pirimiphos. This compound was found in concentrations at least twice as high as those reported in other countries. On the other hand, the frequency of PNP detection suggests that the population has recently been exposed to parathion or parathion-methyl.

The DEAMPY concentrations showed significant negative correlations with Er-AChE activity, indicating a possible health risk of pirimiphos even at environmental exposure levels. The significant correlation observed between 3-BPA and lower Er-AChE also indicates an effect of pyrethroid pesticides on the AChE system. This effect is clearly related to pyrethroid pesticides and not to the correlation with OP pesticides.

Supplementary Information The online version contains supplementary material available at https://doi.org/10.1007/s11356-021-14397-1.

Availability of data and materials The datasets used and/or analyzed during the current study are available from the corresponding author on reasonable request.

Author contribution Iohanna Filippi: Methodology, investigation, writing - original draft

Natalia Bravo: Methodology, data analysis, writing - original draft

Joan Grimalt: Methodology, data analysis, resources, writing - review and editing, funding acquisition

Mariana Butinof: Conceptualization and funding acquisition

Daniel Lerda: Conceptualization and methodology

Ricardo A. Fernández: Conceptualization and Methodology

Sonia E. Muñoz: Conceptualization, resources, and Supervision

María V. Amé: Conceptualization, resources, supervision, funding acquisition, writing - review and editing

Funding This work was supported by grants from the Agencia Nacional de Promoción Científica y Técnica (FONCyTPICT2015-1784), Secretaría de Ciencia y Técnica (SECyT, UNC, Res. 411/2018), and Project EDCMET (H2020-HEALTH/ 0490-825762) funded by the European Union. The present work is part of the $\mathrm{PhD}$ thesis of I. Filippi, who gratefully acknowledges a fellowship from CONICET.

Agencia Nacional de Promoción Científica y Tecnológica (Grant ref: FONCyT-PICT2015-1784). Principal investigator recipient: Dr. Maria V Amé

Agencia Nacional de Promoción Científica y Tecnológica (Grant ref: UNC, Rs. 411/2018). Principal investigator recipient: Dr. Maria V Amé

Horizon 2020 Framework Programme (Grant ref: H2020-HEALTH/ 0490-825762). Principal investigator recipient: Prof. Joan O. Grimalt

\section{Declarations}

Ethics approval and consent to participate Written informed consent was obtained from the subjects who agreed to participate in the study. The proposal was approved by the Ethics Review Committee of Hospital Nacional de Clínicas and is enrolled in the Ethics Committee of Health Investigations of the Córdoba Province (RePIS N 1582 and 044/10).

Consent for publication Not applicable

Competing Interests The authors declare no competing interests. 


\section{References}

Abu-Qare AW, Abou-Donia MB (2000) Urinary excretion of metabolites following a single dermal dose of [14C]methyl parathion in pregnant rats. Toxicology 150(1-3):119-127. https://doi.org/10.1016/ S0300-483X(00)00250-X

Arcury TA, Grzywacz JG, Isom S, Whalley LE, Vallejos QM, Chen H, Galván L, Barr DB, Quandt SA (2009) Seasonal variation in the measurement of urinary pesticide. Int J Occup Environ Health 15(4):339-350. https://doi.org/10.1179/oeh.2009.15.4.339

Barr DB (2008) Biomonitoring of exposure to pesticides. J Chem Health Saf 15(6):20-19. https://doi.org/10.1016/j.jchas.2008.07.001

Barr DB, Barr JR, Maggio VL, Whitehead RD, Sadowski MA, Whyatt M, Needham LL (2002) A multi-analyte method for the quantification of contemporary pesticides in human serum and plasma using high-resolution mass spectrometry. J Chromatogr B778:99-111. https://doi.org/10.1016/s0378-4347(01)00444-3

Becaria Coquet J, Caballero VR, Camisasso MC, González MF, Niclis C, Román MD, Muñoz SE, Leone CM, Procino F, Osella AR, Aballay LR (2020) Diet quality, obesity and breast cancer risk: an epidemiologic study in Córdoba, Argentina. Nutr Cancer 72:1026-1035. https://doi.org/10.1080/01635581.2019.1664601

Bjørling-Poulsen M, Andersen HR, Grandjean P (2008) Potential developmental neurotoxicity of pesticides used in Europe. Environ Health 22:7-50. https://doi.org/10.1186/1476-069X-7-50

Bolognesi C (2003) Genotoxicity of pesticides: a review of human biomonitoring studies. Mutat Res 543:251-272. https://doi.org/10. 1016/s1383-5742(03)00015-2

Bolognesi C, Parrini M, Bonassi S, Ianello G, Salanitto A (1993) Cytogenetic analysis of a human population occupationally exposed to pesticides. Mutat Res 285:239-249. https://doi.org/10.1016/ 0027-5107(93)90112-S

Braeckman RA, Audenaert F, Willems JL, Belpaire FM, Bogaert MG (1983) Toxicokinetics of methyl parathion and parathion in the dog after intravenous and oral administration. Arch Toxicol 54:71-82. https://doi.org/10.1007/BF00277817

Bravo N, Grimalt JO, Bocca B, Pino A, Bin M, Brumatti LV, Rosolen V, Barbone F, Ronfani L, Alimonti A, Calamandrei G (2019) Urinary metabolites of organophosphate and pyrethroid pesticides in children from an Italian cohort (PHIME, Trieste). Environ Res 176: 108508. https://doi.org/10.1016/j.envres.2019.05.039

Bravo N, Grimalt JO, Mazej D, Tratnik JS, Sarigiannis DA, Horvat M (2020a) Mother/child organophosphate and pyrethroid distributions. Environ Int 134:105264. https://doi.org/10.1016/j.envint.2019. 105264

Bravo N, Peralta S, Grimalt JO, Martínez MA, Rovira J, Schuhmacher M (2020b) Organophosphate metabolite concentrations in maternal urine during pregnancy. Environ Res 176:1-6. https://doi.org/10. 1016/j.envres.2019.109003

Butinof M, Fernández RA, Lerda D, Lantieri MJ, Filippi I, Díaz MP (2019) Biomonitoreo en exposición a plaguicidas y su aporte en vigilancia epidemiológica en agroaplicadores en Córdoba, Argentina. Gac Sanit 33(3):216-221. https://doi.org/10.1016/j. gaceta.2017.12.002

CASAFE (Cámara de Sanidad Agropecuaria y Fertilizantes) (2016) Datos del Mercado Argentino de Fitosanitario.https://www.casafe. org/pdf/2018/ESTADISTICAS/Informe-Mercado-Fitosanitarios2016.pdf. Accessed 10 February 2020 .

Davis MD, Wade EL, Restrepo PR, Roman-Esteva W, Bravo R, Kuklenyik P, Calafat AM (2013) Semi-automated solid phase extraction method for the mass spectrometric quantification of 12 specific metabolites of organophosphorus pesticides, synthetic pyrethroids, and select herbicides in human urine. J Chromatogr B929: 18-26. https://doi.org/10.1016/j.jchromb.2013.04.005
Dewailly E, Forde M, Robertson L, Kaddar N, Laouan Sidi EA, Côté S, Gaudreau E, Drescher O, Ayotte P (2014) Evaluation of pyrethroid exposures in pregnant women from 10 Caribbean countries. Environ Int 63:201-206. https://doi.org/10.1016/j.envint.2013.11.014

Ellman GL, Courtney KD, Andres V, Featherstone RM (1961) A new and rapid colorimetric determination of acetylcholinesterase activity. Biochem Pharmacol 7:88-95. https://doi.org/10.1016/00062952(61)90145-9

Fukuto TR (1990) Mechanism of action of organophosphorus and carbamate insecticides. Environ Health Perspect 87:245-254. https://doi. org/10.1289/ehp. 9087245

Garí M, González-Quinteiro Y, Bravo N, Grimalt JO (2018) Analysis of metabolites of organophosphate and pyrethroid pesticides in human urine from urban and agricultural populations (Catalonia and Galicia). Sci Total Environ 622-623:526-533. https://doi.org/10. 1016/j.scitotenv.2017.11.355

Gentile N, Mañas F, Bosch B, Peralta L, Gorla N, Aiassa D (2012) Micronucleus assay as a biomarker of genotoxicity in the occupational exposure to agrochemicals in rural workers. Bull Environ Contam Toxicol 88:816-822. https://doi.org/10.1007/s00128-0120589-8

Hancock DB, Martin ER, Mayhew GM, Stajich JM, Jewett R, Stacy MA, Scott BL, Vance JM, Scott WK (2008) Pesticide exposure and risk of Parkinson's disease: a family-based case-control study. BMC Neurol 8:1-12. https://doi.org/10.1186/1471-2377-8-6

Heffernan AL, English K, Toms LML, Calafat AM, Valentin-Blasini L, Hobson P, Broomhall S, Ware RS, Jagals P, Sly PD, Mueller JF (2016) Cross-sectional biomonitoring study of pesticide exposures in Queensland, Australia, using pooled urine samples. Environ Sci Pollut Res 23:23436-23448. https://doi.org/10.1007/s11356-0167571-7

Hernández AF, Parrón T, Tsatsakis AM, Requena M, Alarcón R, LópezGuarnido O (2013) Toxic effects of pesticide mixtures at a molecular level: their relevance to human health. Toxicol. 307:136-145. https://doi.org/10.1016/j.tox.2012.06.009

Heudorf U, Angerer J (2001) Metabolites of Pyrethroid Insecticides in urine specimens: current exposure in an urban population in Germany. Environ Health Perspect 109(3):213-217. https://doi. org/10.1289/ehp.01109213

INTA (Instituto de Tecnología Agropecuaria/Secreataría de Agricultura, Ganadería y Pesca (2009) Estudios socio-economicos de la sustentabilidad de los sistemas de producción y recursos naturales. Zonas Agroeconómicas Homogéneas Córdoba. https://inta.gob.ar/ sites/default/files/script-tmp-inta-zonas_agroeconmicas_09cba.pdf. Accessed 24 March 2020.

Joint Meeting on Pesticide Residues (JMPR) FAO/WHO (Food and Agriculture Organization of the United Nations/World Health Organization) (2006) http://www.fao.org/agriculture/crops/ thematic-sitemap/theme/pests/lpe/en/. Accessed 20 February 2020

Joint Meeting on Pesticide Residues (JMPR) FAO/WHO (Food and Agriculture Organization of the United Nations/World Health Organization) (2020) http://www.fao.org/agriculture/crops/ thematic-sitemap/theme/pests/lpe/en/. Accessed 15 February 2020

Jokanović M (2018) Neurotoxic effects of organophosphorus pesticides and possible association with neurodegenerative diseases in man: a review. Toxicology. 1(410):125-131. https://doi.org/10.1016/j.tox. 2018.09.009

Katsikantami I, Colosio C, Alegakis A, Tzatzarakis MN, Vakonaki E, Rizos AK, Sarigiannis DA, Tsatsakis AM (2019) Estimation of daily intake and risk assessment of organophosphorus pesticides based on biomonitoring data - the internal exposure approach. Food Chem Toxicol 123:57-71. https://doi.org/10.1016/j.fct.2018. 10.047

Koch HM, Hardt J, Angerer J (2001) Biological monitoring of exposure of the general population to the organophosphorus pesticides chlorpyrifos and chlorpyrifos-methyl by determination of their specific 
metabolite 3,5,6-trichloro-2-pyridinol. Int J Hyg Environ Health 204:175-180. https://doi.org/10.1078/1438-4639-00082

Koureas M, Tsakalof A, Tsatsakis A, Hadjichristodoulou C (2012) Systematic review of biomonitoring studies to determine the association between exposure to organophosphorus and pyrethroid insecticides and human health outcomes. Toxicol Lett 210:155-168. https://doi.org/10.1016/j.toxlet.2011.10.007

Lantieri MJ, Butinof M, Fernández RA, Stimolo MI, Blanco M, Díaz MP (2011) Work practices, exposure assessment and geographical analysis of pesticide applicators in Argentina. In: Stoytcheva M (ed) Pesticides in the modern world - effects of pesticides exposure. Croatia, pp 115-138. https://www.intechopen.com/books/ pesticides-in-the-modern-world-effects-of-pesticides-exposure/ work-practices-exposure-assessment-and-geographical-analysis-ofpesticide-applicators-in-argentina

Le Grand R, Dulaurent S, Gaulier JM, Saint-Marcoux F, Moesch C, Lachâtre G (2011) Simultaneous determination of five synthetic pyrethroid metabolites in urine by liquid chromatography-tandem mass spectrometry: application to 39 persons without known exposure to pyrethroids. Toxicol Lett 210(2):248-253. https://doi.org/10. 1016/j.toxlet.2011.08.016

Leng G, Leng A, Kuhn K-H, Lewalter J (1997) Human dose-excretion studies with the pyrethroid insecticide cyfluthrin : urinary metabolite profile following inhalation. Xenobiotica 27:1273-1283

Lewis RC, Cantonwine DE, Del Toro LV, Calafat AM, Valentin-Blasini L, Davis MD, Montesano MA, Alshawabkeh AN, Cordero JF, Meeker JD (2015) Distribution and determinants of urinary biomarkers of exposure to organophosphate insecticides in Puerto Rican pregnant women. Sci Total Environ 512-513:337-344. https://doi.org/10.1016/j.scitotenv.2015.01.059

MAGyP (Ministerio de Agricultura, Ganadería y Pesca) (2018) Estimaciones Agrícolas. Argentina: http://datosestimaciones. magyp.gob.ar/reportes.php?reporte=Estimaciones. Accessed 24 January 2020

Manthripragada AD, Costello S, Cockburn MG, Bronstein JM, Ritz B (2010) Paraoxonase 1 (PON1), agricultural organophosphate exposure, and Parkinson disease. Epidemiology 21(1):87-94. https://doi. org/10.1097/EDE.0b013e3181c15ec6

McKinlay R, Plant JA, BellJNB VN (2008) Endocrine disrupting pesticides: Implications for risk assessment. Environ Int 34:168-183. https://doi.org/10.1016/j.envint.2007.07.013

Moltoni L (2012) Evolución del mercado de herbicidas en Argentina. http://inta.gob.ar/documentos/economia-y-desarrolloagroindustrial-boletin-1-2-evolucion-del-mercado-en-argentina. Accessed 13 January 2020

Morgan MK (2015) Predictors of urinary levels of 2,4dichlorophenoxyacetic acid, 3,5,6-trichloro-2-pyridinol, 3phenoxybenzoic acid, and pentachlorophenol in 121 adults in Ohio. Int J Hyg Environ Health 218:479-488. https://doi.org/10. 1016/j.ijheh.2015.03.015

Morgan DP, Hetzler HL, Slach EF, Lin LI (1977) Urinary excretion of paranitrophenol and alkyl phosphates following ingestion of methyl or ethyl parathion by human subjects. Arch Environ Contam Toxicol 6:159-173

Olsson AO, Nguyen JV, Sadowski MA, Barr DB (2003) A liquid chromatography/electrospray ionization-tandem mass spectrometry method for quantification of specific organophosphorus pesticide biomarkers in human urine. Anal Bioanal Chem 376:808-815. https://doi.org/10.1007/s00216-003-1978-y

Panuwet P, Prapamontol T, Chantara S, Thavornyuthikarn P, Montesano MA, Whitehead RD, Barr DB (2008) Concentrations of urinary pesticide metabolites in small-scale farmers in Chiang Mai Province, Thailand. Sci Total Environ 407:655-668. https://doi. org/10.1016/j.scitotenv.2008.08.044
Payne-Sturges D, Cohen J, Castorina R, Axelrad DA, Woodruff TJ (2009) Evaluating Cumulative Organophosphorus Pesticide Body Burden of Children: A National Case Study. Environ Sci Technol 43:7924-7930

Perry MJ, Venners SA, Barr DB, Xub X (2007) Environmental pyrethroid and organophosphorus insecticide exposures and sperm concentration. Reprod Toxicol 23:113-118. https://doi.org/10.1016/j. reprotox.2006.08.005

Phung DT, Connell D, Miller G, Hodge M, Patel R, Cheng R, Abeyewardene M, Chu C (2012) Biological monitoring of chlorpyrifos exposure to rice farmers in Vietnam. Chemosphere 87:294-300. https://doi.org/10.1016/j.chemosphere.2011.11.075

Ratelle M, Coté J, Bouchard M (2015) Time profiles and toxicokinetic parameters of key biomarkers of exposure to cypermethrin in orally exposed volunteers compared with previously available kinetic data following permethrin exposure. J Appl Toxicol 35:1586-1593

Raymer JH, Studabaker WB, Gardner M, Talton J, Quandt SA (2014) Pesticide exposures to migrant farmworkers in Eastern NC: detection of metabolites in farmworker urine associated with housing violations and camp characteristics. Am J Ind Med 57:323-337. https://doi.org/10.1002/ajim.22284

Rohlman DS, Anger WK, Lein PJ (2011) Correlating neurobehavioral performance with biomarkers of organophosphorus pesticides exposure. Neurotoxicol. 32(2):268-276. https://doi.org/10.1016/j.neuro. 2010.12.008

Sams C, Jones K (2012) Biological monitoring for exposure to deltametrhin: A human oral dosing study and background levels in the UK general population. Toxicol Lett 213:35-38. https://doi.org/ 10.1016/j.toxlet.2011.04.014

Saoudi A, Fréry N, Zeghnoun A, Bidondo ML, Deschamps V, Göen T, Garnier R, Guldner L (2014) Serum levels of organochlorine pesticides in the French adult population: the French National Nutrition and Health Study (ENNS), 2006-2007. Sci Total Environ 472: 1089-1099. https://doi.org/10.1016/j.scitotenv.2013.11.044

Schettgen T, Alt A, Esser A, Kraus T (2015) Current data on the background burden to the persistent organochlorine pollutants $\mathrm{HCB}, \mathrm{p}$, p'-DDE as well as PCB 138, PCB 153 and PCB 180 in plasma of the general population in Germany. Int J Hyg Environ Health 218(4): 380-385. https://doi.org/10.1016/j.ijheh.2015.02.006

Trunnelle KJ, Bennett DH, Tulve NS, Clifton MS, Davis MD, Calafat AM, Moran R, Tancredi DJ, Hertz-Picciotto I (2014) Urinary pyrethroid and chlorpyrifos metabolite concentrations in Northern California families and their relationship to indoor residential insecticide levels, part of the study of use of products and exposure related behavior (SUPERB). Environ Sci Technol 48(3):19311939. https://doi.org/10.1021/es403661a

Wang L, Liu Z, Zhang J, Wu Y, Sun H (2016) Chlorpyrifos exposure in farmers and urban adults: Metabolic characteristic, exposure estimation, and potential effect of oxidative damage. Environ Res 149: 164-170. https://doi.org/10.1016/j.envres.2016.05.011

Woollen BH, Marsh JR, Laird WJD, Lesser JE (1992) The metabolism of cypermethrin in man: differences in urinary metabolite profiles following oral and dermal administration. Xenobiotica 22:983-991

Yusa V, Millet M, Coscolla C, Pardo O, Roca M (2015a) Occurrence of biomarkers of pesticide exposure in non-invasive human specimens. Chemosphere 139:91-108. https://doi.org/10.1016/j.chemosphere. 2015.05.082

Yusa V, Millet M, Coscolla C, Roca M (2015b) Analytical methods for human biomonitoring of pesticides. A review. Anal Chim Acta 891: 15-31. https://doi.org/10.1016/j.aca.2015.05.032

Publisher's note Springer Nature remains neutral with regard to jurisdictional claims in published maps and institutional affiliations. 